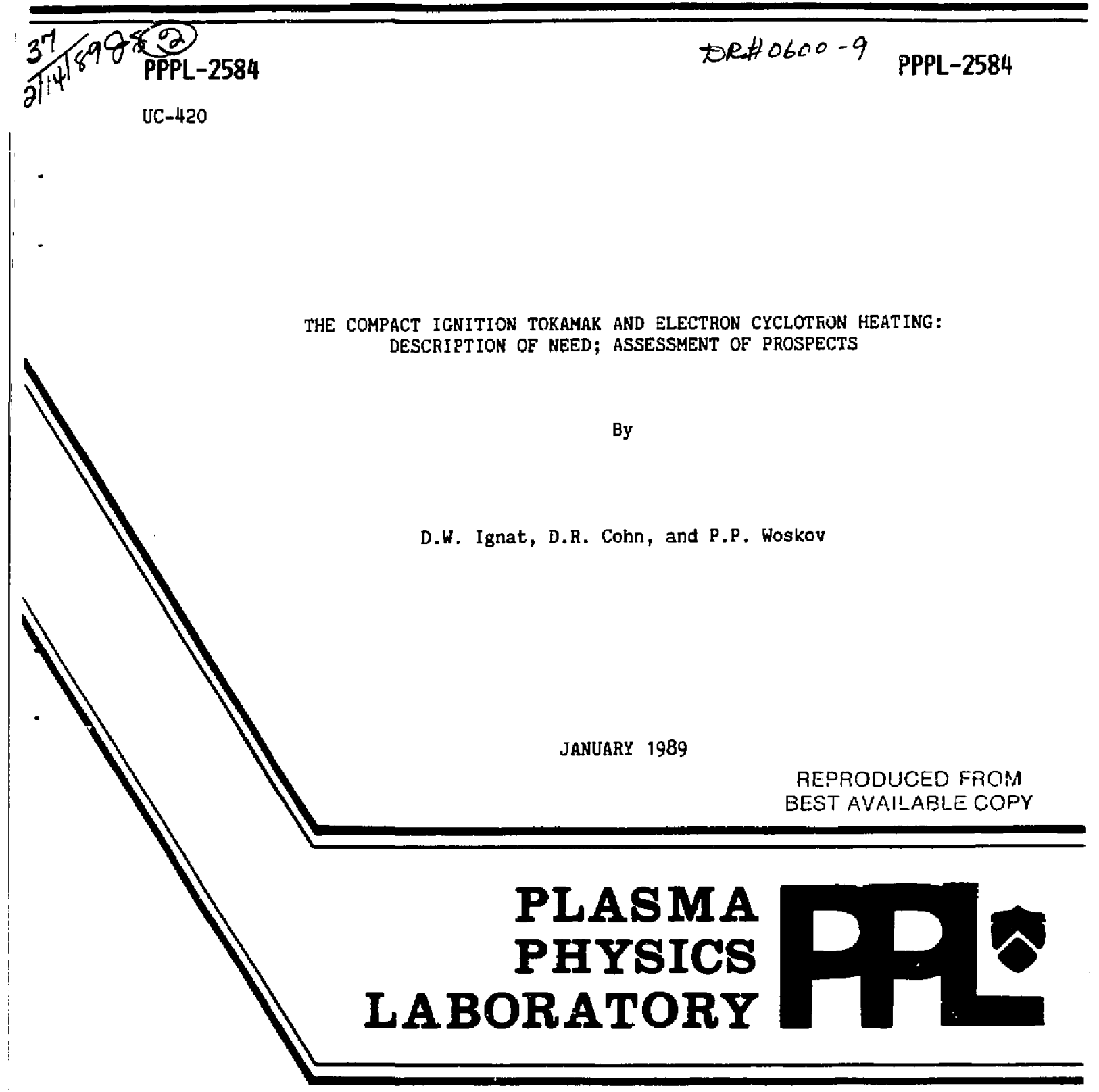

PRINCETON UNIVERSITY , PRINCETON, NEW JERSEY

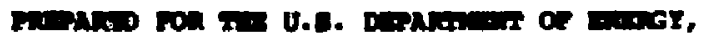

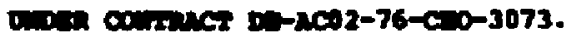




\title{
DISCLAMMER
}

This report was preparod as an account of work sponsored by $2 \mathrm{an}$ agency of the United Statca Government. Neither the Uniled Stales Govesnment nor any agency thersol, nor any of their warranty, exptess of implied, of assumes any legal liaisility or responsi-

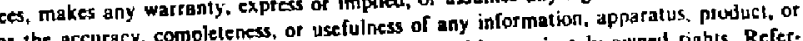
bility for the accuracy, completeness, of usefulness af any inime privately owned rights. Referprocess diselosed. or represents that its use would nol ins, or service by trade name. Lademark, ence hercin en any specific comnercial product, praces, or ser imply its endorsement, recommanufacturer, or otherwise does not necessarily constite or mp agency thereof. The views mendation, or favoring by the United States Government or any agency thereol. The the and opinions of authors expressod herein do not

Unitod States Gowernment or any agency thereof.

\section{The Compact Ignition Tokamak and Electron Cyclotron Heating: Description of Need; Assessment of Prospects}

\author{
D. W. Ignat \\ Plasma Physics Laboratory, Princeton University \\ Princeton, New Jersey \\ and \\ D. R. Cohn and P. P. Woskov \\ Plasma Fusion Center, Massachusetts Institute of Technology \\ Cambridge, Massachusetts
}

\begin{abstract}
The CIT will benefit from auxiliary heating of 10 to $40 \mathrm{MW}$. The schedules of both the CIT construction project and the operating plan contain adequate time to develop and implement ECH systems based on the gytotron and the induction free electron laser (IFEL). Each approach has advantages and is the object of R\&D at the level of many millions of dollars per year. While the gyrotron is further advanced in terms of power and pulse length achieved, rapid progress is scheduled for the IFEL, including experiments on tokamaks. Plans of CIT, gyrotron, and IFEL make 1992 an appropriate time frame to commit to one or both systems.
\end{abstract}




\section{Requirements}

Wo divide rexpirements into physics and engineering. In general, physics is related th energy flows in the plasma, and engineering is related to fows mutside the vacumm vessel, including the possible motion of tritium away from the vessel.

\subsection{Physics}

The basic CIT physics requirements for auxiliary heating can be specified by three parameters: power, frequency, and time. The nominal values for the full-performance tevice are $40 \mathrm{MW}, 280 \mathrm{GHz}$, and 10 seconds. The following sections develop the motivation for these numbers. Section 1.1.1 discusses power based on the predictions of scaling laws for the size of the minimum anxiliary power required to reach ignition. Sections 1.1.2 and 1.1.3 discuss the frequency derived from the several levels of magnetic field needed for uperatiem. and the requirement for modulation. Section 1.1.4 lists the pulse length. Finally, the second harmonic option is examined in 1.1.5.

The nature of the CIT design is summarized in Table 1, "Selected Parameters of the C:IT Design."

\subsubsection{Predictions of Scaling Laws}

Figure I plots contours of required auxiliary power in temperature-density space, assuming Kaye-Goldston confinement.' The maximum required auxiliary power lor maintaining an equilibrium is about $6 \mathrm{MW}$. A higher power is required to reach ignition in a sufficiently short time, owing to the effects of heat capacity.

There is uncertainty in plasma confinement. The Kaye-Goldston law of Fig. $I$ is on the optimistic end of the range. A law of Goldston ${ }^{2}$ from the Aachen meeting often is used in analyzing results. If an enhancement of a factor of 1.8 over the Goldston scaling is assumed, then CIT would not reach ignition, as shown in Fig. 2.

The cunfinement of Fig. 2 may mut lead to ignition, but the fusion energy nultiplication (Q) can be large, as shuwn in Fig. 3. These curves are contuurs of constant $Q$ for the same parameters as Fig. 2, including 1.8 times Goldston 
confinement. Auxiliary heating power of $25 \mathrm{MtV}$ yields a $Q$ of about 10. A steady-state priwer of $60 \mathrm{M} W \mathrm{~W}$ wold be required to reach the estimated "peral ional limits on beta and de'tnity.

If the enhancement over (iuldston scaling is a factor of 2 , then ignition becomes pussible. Enhancements of this magnitude are consistent with some of the results funnd in large tokamaks. The Tokamak Fusion Test Keaclor (TFTK) has been able to uperate in a supershot' mode, in which an enhancement of confinement of approximately 3 is found in low-initial-density. neutral-beam-fueled discharges. While this low-initial-density mode, as it is known in TFTR, may not lead to ignition, it does offer hope of finding higher confinement than predicted by the Goldston scaling.

The impact of scaling laws is that auxiliary heating powers from $10 . \mathrm{MW}$ in $10 \mathrm{MIV}$ may be required to make high- $Q$ or ignited plasma. The range quoted is broad in parallel with the range of uncertainty.

\subsubsection{Operating Magnetic Fields}

Oprrations at 7 through 11 Tesla Although the engineering design of (IT is aimed al 10 Tesla for a large number of pulses (3000), operation al 11 Testa for fewer pulses (yet to be determined) is also an important design goal. The motivation is une final increase of the intrinsic performance if the goal of ignition is slighely beyond the reach of the 10-Tesla parameters.

Operation at 10 Tesla ard 11 Tesla is the requirement for the trokamak systems (magnet coils, vessel, structure), but the initial construction projert will deliver a power supply rapable of 7 Tesla.

There are several avemues upgrading the power system, sume of which are under discussion with the Suviet Union. For the moment, our planning should be based on the assumption that the 10 Tesla capability will follow the initial 7 Tesle installation by 3 years.

Another impurtant feat ure of the $7 / 10$ Tesla transition is that, arcording 6 , the engineering philosuphy, the number of pulses at $7 \mathrm{~T}$ is virtually unlimited by fatigue, whereas at $10 \mathrm{~T}$ the fatigue limit is in the range of 3000 pulses. Therefure. regardless of the eventual plan for upgrading puwer and energy, there will be extensive operation in the $T T$ range to gain experience with ('IT. 
Heating During Ramp The pulse length of the machine is short to minimize the project cost. As a result, the flat top pulse length is 5 seronds. This time, while sufficient to reach afd study ignition, dows not contain a large margin for special formation terhnigutes ar shatting down the dissharge smuruthly. Therefore, we consider the pussibility of heating during the ramp-up and ramp-down phase.

Figure 4 shows that an extra 3 seconds on the front side of the 10 Tesla flat top period can be wbtained by operating when the field gets to $80 \%$ of thr maximum and the current attains $1 / 2$ of the nominal value. A similar possibility exists on the ramp-down side. Figure 5 gives a similar result for the II Tesla operation. although the flat top is shorter and the time from $80 \%$ $10100 \%$ of oprerating field is longer. Figure 6 show's the 7 Tesila case.

The frepuency can be calculated approximalely from the electron cyclotron resonance being proportional to magnetic field at $28 \mathrm{GHz}$ per Tesla. Thernal and Denpler ellects exist, but an be assumed small in the appruach to heating being considered. Best results are expected with lieating at the "enter, sw there may be a benctit 1o sweeping the frequency of the microwave power with field. Thus, a nominal in Tesla case involves a ramp from $224 \mathrm{GHz}$ to $2806 \mathrm{GHz}$ in 3 secinds, fold for 5 seconds, and ramp back to $224 \mathrm{GHz}$ in 3 seconds. The few I] Tesla experiments need $246 \mathrm{GHz}$ ramped to $308 \mathrm{GHz}$ and back. The majurity of experiments, introlving the 7 Tesla maximum field, needs $160 \mathrm{GHz}$ ramped $211200 \mathrm{GHz}$ and back.

Fixed Frequency, with Moving Resonance Ramping the frequency up and down requires a state of technolugy that is quite advanced considering the alssence of any suitable source in this range at the moment. The problem with ramping is probably variations in microwave impedance with frequency, leading tor resonant reflections and local power concentrations in the microwave generator and transmission systerr.

On the other hand. it is plausible that the plasma is not so demanding that the heat must be depositud exactly in the center. In fart, the elongated rquilibria of (IT feature a largo sawtouth mixing radius, equal to more than $60 \%$ of the minur radius. The effect of heating in the exact center can be abtained for heating within $60 \%$ of the minor radius of the center. Therefore, a choice of freguency that is the mean of the center frequencies of interest appears acceptable. 
Fir 10 Tesla experiments the mean is 250 Cillz: for 11 T'esla. the mean is 28Il Gitz: linally, at $i$ Tesla, the mean is I80 (iHz.

If a fixed frequency is used in a changing field. then the plasma must fill 1.he region adequately. This point is addressed in Figs. 7 and 8 . The Trokamak Sionulation ('inde ( $\mathrm{TSC}^{3}$ was used to make these ralculations of the evolution of the equililorium. Note that the final location of the plasma is reached 2 seconds from initiation, while the heating during the ramp in Fig. 4 needs to start I seconds after initiation.

Fixed Frequency, with Changing Launch Angle The Doppler shift can bo used lo adjust the locatiun of heating. In some circumstances, which involve launch frum the top of the tokarnak, the adjustment can be extremely large: Nazzucatu it al. find that a 10.5 Tesla compart ignition device can be heated surecessfilly with only 190 Gllz.

A versiun of this tcehnjegue can be used to keep rentral heating while the field is changing and the frequency is constant. $A$ mechanism to steer the $E: C H$ launch angle relative to the magnetic field can be imagined inside a hurizontal port. Fstimates by M. Porkulab are that a 20 degree swing would be sufficient for following the last $20 \%$ ramp of the field. ${ }^{5}$

Summary on Operating Magnetic Fields In summary, the heating needs Io be offertive at nominal fields of 7,10 , and 11 Tesla. In addition. the henting should be effective as the magnetic field ramps through the last $20 \%$ of the numinal peak magnetic field. It appears that this could be handled by two separate frequencies, a notnimal $180 \mathrm{GHz}$ system for 7 Tesla and a nominal 280 GHz system for 10 and 11 Tesla. However, predicting the range of possible operating situations that will be desired is difficult, and tunability in small sleps through this range weuld be an advantage, whether on the time scale of alays or fractions of a second. Some effective tunability nay be practical by rhanging the launch angle.

\subsubsection{Rapid Modulation of Frequency and Power}

The ability to place the resonanes at the o I surface, and the q 2 surface costd loe important, allowing interaction with $31 \mathrm{Hl}$ ) activity in the plasma. 
There is some experimental and theoretical evidence for improved plasma performance under such situations. It may atso be desirable to heat at different locations at different tirtes. Howeter, this capability represents a new level of demand on the technolugies that have not approarhed the basic requirements of high frequency and high poxser. Fine scale controi of frequency and power is desirable once the basic requirements can be met.

Simple modulation of power should not be difficult. and it is expected tor be one of the fundamental controls of plasma near ignition.

Variation on miderate time scales $(0.5 \mathrm{sec})$ of the location of the power deposition may be possible with an aiming adjustment on the vertical location of the geometrical ray path.

\subsubsection{Pulse Length}

The discussion above on the waveform of field and current shows that the theating shuild be available for approximately 10 seconds. Of this time, 5 seconds represent flat-top time, and the other 5 seconds would be used during ramp-up and ramp-diown.

This numinal 10 second pulse length applies to initial operations un ('IT at $T \mathrm{~T}$, in which power and energr are limited. The 10 second pulse length also applies to the 10/11 Tesla operation with full power and energy installed. However, when full puster and energy are installed, very long pulses are possible at the $T$ Tesla magnetic field. For such pulses, it is possible that heating times on the scals of 20 seconds world be desirable.

\subsubsection{Second Harmonic Heating}

First harmonic heating (fundamental) has been discussed, rather than secund hasmonic. This is because significant power is now avilable at $1.40 \mathrm{GHz}$ with gyrotrons, which is comparable to the $180 \mathrm{GHz}$ required for $\mathrm{T} T$. A second harmonjc system is 360 to $560 \mathrm{GHz}$, representing an enormous advance in the state of the art.

However, the physics advantage wo secund harmonic heating is the increase in density that can be heated. Higher density is assoriated with better confinement, a rise in the product $n \cdot \tau \cdot T$ and an increased range of plasma parameters fur ignition. Hased on empirical evidence, (IT assumes that the 
density will be limited to

$$
\overline{n_{e}}<2.0 B /\left(R q_{e}\right) \quad,
$$

where $n_{e}$ is in units of $10^{20}$ particles per $\mathrm{m}^{3}, B$ is in Tesla, $R$ is in meters. ${ }^{5}$ The engineering $q . q_{e 1}$ is defined as

$$
q_{\mathrm{r}}=5 a^{2} \kappa B /(R I) \quad,
$$

with $f$ in MA and $k$ representing the elongation. The basis for this limit is not fully explained by theory, although it is generally believed that it is related to $B /(R q)$ being proportional to current density, and ther fore power input from th plasma current. If true, extra power input could presumably allow the density to rise. However, data proving this have not emerged.

At $10 \mathrm{~T}$, the empirical density limit yields $5 \times 10^{20}$ per cubic meter for the line-averaged density, while $280 \mathrm{GHz}$ should propagate from launch on the outside midplane (ordinary mode) to $9.7 \times 10^{20}$. The two density limits are close enough that calculations of the refractive effects are necessary to examine the feasibility. The calculations show that arreptable trajectories of the ECH energy occur up to 0.8 of the cutoff density $=$ or $8 \times 10^{20}$. Therefore, first harmonic loxks satisfactory for useful heating at the nominal ClT density limit. However, advancing beyond this density would not be posible with 280 GHz.

At $7 \mathrm{~T}$, the empirical limit on average density limit is $3.5 \times 10^{20}$, but. the practical propagating limit for $180 \mathrm{GHz}$ is about $3.2 \times 10^{20}$ peak density. Therefore, a $180 \mathrm{GHz}$ source for 7 Tesla actually linits the density to slightly less than the "2B/Rq" empirical formula.

\section{$1.2 \quad$ Engineering}

\subsubsection{Space Requirements}

The ECH prower must be transmitted into a port with clear dimensions of approximately 35 isy $100 \mathrm{~cm}$. The total power shculd be up to $15 \mathrm{MW}$ per port. This means an average transmitted power density of $10 \mathrm{~kW} / \mathrm{cm}^{2}$, assuming about half the port area is filled with EC'H couplers.

The port size comes from the overall parameters of the design. The re. quirement on $: 5$. NW per port comes from the apparent ability of EC:H power 
to achieve this high power density, and the fact that EC'H is to be a supplement to the original ion cyclotron heating (IC $1:$ ) system. which requites three perts for $10 \mathrm{XlW}$. If ECH has to use more purts than 1 pee $10.11 \mathrm{~K}$, its use as a supplement will be difficult owing to limitations on the number of ports axailable for heating.

The equipment to generate and transmit the EC:H prower must fit intu the site of ('IT, which includes existing TFTK buildings. Surrounding land can be used. within limits imposed by the existing site.

\subsubsection{Safety}

Tritium streaming up the waveguides connecting the ECH power source(s) to the vacisum chamber is the major safety consideration. Numerical requirements nevil to be developed.

The design abjective for CIT on radiation safety issues is a maximum site boundary dose of 10 millirem per year in normal operation, and a maximum site boundary dose of $5 \mathrm{rem}$ in case of an extremely unlikely event, or 1 rem in the case of an unlikely event. An extremely unlikely event has a probability in the range of $10^{-6}$ to $10^{-4}$ per year. An unlikely event has a probability in the range of $10^{-4}$ to $10^{-2}$ per year.

There are two basic approaches to the waveguides: with windows and withont windows. Gyrotron installations of the past have used windows, and engineers working on gyrotrons prefer windows for the future. However, R\&D on windows at this high frequency will be required, and is not now funded. The IFEL inst:llation at the Microwave Tokamak Experiment (MTX) at LL.VL dues not have windows, and the planning for an IFEL on CIT does not include windows.

If there are go windows, a differential pumping sy'stem with fast valves for more accurately, fast conductance limiters) appears to be possible. There has been no design work on such systems for the CIT context.

In either case, waveguides may require a "jacket" as a tritium barrier. This will obviously make the design more cumbersome. Issues related to tritium will be explored in the near future. 


\subsubsection{Reliability}

('l' $[$ has formal requirements on reliability for all systems, expressed in terms of a low probability for forced shutdown of sperations from fallures. The EC'H system would have lo match these requirements.

For example. the flugust 5,1988 draft of the Systems Requirements Document states the following relative to ECH:

1. There shall be [w credible failure modes $\left(P>10^{-6}\right)$ for the ECH system which, directly or indirectly, would compromise the (:IT mission by precluding operation at 10 Tesla and $11 \mathrm{MA}$ for a period in excess of 1 ralendar year.

2. All credible failure modes shall be repairable with equipment funded in the construction pruject.

3. The downtime for unsrheduled maintenance of the EC'H system stall not exceed 2.7 hours per thousand hours of operation per $10 \mathrm{MW}$ of installed power.

4. During full power operation (> $7 \mathrm{~T}$ ) the probability of not successfully acquiring and archiving the necessary subset of data for achieving the goal of a given shot duc tos an axisilaly related to the EC:H system or of experiencing a failure in the EC'11 system which precludes the initiation of the next shot shall be less than 13.8 per thousand shots per $10 \mathrm{NW}$ of installed power.

Other than reliability requirements as expressed above, these is no requireInent related to reliability on the desired amount of power to come from one source. It is sometimes believed that a unit size smaller than $1 \mathrm{MW}$ (or so) will lead to an unreliable system of $10 \mathrm{MW}$ in size, and that the iarger the power from a unit the better. This thought may turn out to be valid, but it remains to be demunstrated. 


\section{Schedule and Cost}

\section{$2.1 \quad$ CIT Schedule}

\subsubsection{Construction and Operating;}

The CIT Project Schedule, as of autumn 1988. is a reference for considerations pertaining to R\&D on ECH sources. Arcording tw that schechle, operation with plasma stirts at a. $T$ Tesla maximum field in Jily of 1996. The luasic machine will be capable of 10 Tesla for a nominal 3000 puises, and 11 Tesla for some limited number of discharges. The limitation to 7 Tesla operation cumes from installed equipment fo- energy sturage and conversion. The additional funding for opezation at 10 and 11 Tesud is in the range of $570 \mathrm{XI}$. Since the funds have not been identified, the time required to bring the CIT to I0) Tesla might be in the range of four ycars.

There are operating considerations as well. Simce experience will be needed with the equipment and the plasma. and since the number of shits per day will be on the order of ten. four years of preparation for the highest held is reasonable.

Therefore, we estimate a requirement for an EC'H system capable of heating a $i$ Tesla plasma in 1996, and a 10/11 Tesla plasma after a time. depending wn funding. Assuming four years to specify, construct, and install the EC:H system, the R\&D should be finished in 1992, with some continuing $R \& D$ an the higher frequency in progress until 1996.

\subsubsection{Possible R\&D Plans}

K\&-D could be aimed strictly at the CIT schedule, meaning a source suitable for $7 \mathrm{~T}$, ready for design and construction work in 1992, with contisuing $\mathrm{k} \& \mathrm{D}$ for the higher field until 1996-8. Such a plan appears to be especially sound for the gy'rotron approach, because the gytrotron is already achieving $800 \mathrm{~kW}$ for short pulses at $140 \mathrm{GHz}$, and is directed in the near term to $400 \mathrm{~kW}$ steady-state at $140 \mathrm{GHz}$.

Alternatively, R\&D could aim at the $10 \mathrm{~T}$ condition, believing that, if such a goal is achieverl, modifications for uperation at $i$ Tesla should be relatively simple. This plan would be consistent with the existing IFEL program. which is aimed at $250 \mathrm{GHz}$ on a lıkamak experiment. 
Supporting either plan requires study of practical issues (cost and schedule) and relationships to other programs. The CII' design group favors a plan which focuses on the 10 Tesla implementation, since that is where the ulimate success of CIT is most likely to occur. A possible ontcome of this strategy is that a 10 Tesla source is developed sucressfully, but that retreating to 7 Tesla resonance for the early implementation on CIT appears ton expensive or too time-consuming. In that case, the 10 Tesla source could be used at 7 Tesla. through the technique of Doppler shifting the frequency with off-perpendicular launching. This does introduce complications with steering the beam, and the physics of heating fast electrons.

\subsection{Gyrotron R\&D and Fabrication Schedule and Cost}

The CIT projer! has prepared cost estimates for a complete gurotson program, including $\mathbf{R} \& \mathrm{D}$ and fabrication of a $10 \mathrm{MW}$ installation. ${ }^{i}$ The fabrication project lakes advantage of existing TFTK neutral beam power supplies, which have an estimated value of $\$ 20 \mathrm{M}$, and finds that $10 \mathrm{MW}$ would cost about $\$ 22 \mathrm{M}$.

This cost would have to be duplicated for each additional $10 \mathrm{MW}$ system. Above $30 \mathrm{MW}$, TFTR power supplies would be fully used.

This cost estimate has a detailed logic behind it, including the following important milestones:

- $1 \mathrm{MW}$ short pulse demonstration at the Massachuset ts Institute of Technolngy (MIT) using an experimental $280 \mathrm{GHz}$ tube;

Octuber 1989

- I MW short pulse demonstration at MIJ' using a cw-relevant $280 \mathrm{GHz}$ tube;

February 1992

- I MW long pulse demonstration at $140 \mathrm{GHz}$ at Varian Associates, Inc. February 1991

- 1/2 MW long pulse demonstration at $280 \mathrm{GHz}$ at Varian; October 1992

This schedule allews an inlormed decision in $199^{\circ}$ to proceed with the gyrotion apprcach. 


\subsection{IFEL R\&D Schedule and Construction Cost}

The R\&D on the IFEL insolves advances in IFEL capability and EC'H experiments on the Microwave 'okamak Experiment (MTX) in three phases.

- Single pulse experiments in FY 89 (the US fiscal year starting October 1988, ending September 1989) with $140 \mathrm{GHz}$ and $2.5 \mathrm{GW}$ for 20 nanoseconds. This work will investigate issues related to plasma absorption as well as the functioning of the IFEL. Total energy is $50 \mathrm{~J}$.

- Short burst experiments in FY' 90 with $140 \mathrm{GHz}$ and $3.8 \mathrm{GW}$ at a pulse repetition frequency of $5 \mathrm{kHz}$. The burst time will be 10 milliseconds, For a tulal energy of $5 \mathrm{~kJ}$. Each pulse is to be $35 \mathrm{~ns}$ ling.

- High average power experiments in FY 91 with $250 \mathrm{GHz}$ and $10 \mathrm{GW}$ for 50 ns for a total average power of 2 MW over 0.5 seconds yielding 1 MJ. This will demonstrate the heating technolugg, and its effects on the plasma for heating and profile control. C'urrent drive is a possible topic, also.

- Confinement and current drive ex]eriments using high average power mirrowaves during FY 92.

After completion of these advances in the technology of the IFEL and demonstratiun of results on the UTX, a reliable estimate of cost and scientific perfurmance can be made.

Preliminary estimates of the rosts of a $10 \mathrm{MW}, 280 \mathrm{GHz}$ system for CIT show \$4I M, assuming that a building and prime power are available. A 560 GHz systen, whiclt requires a $15 \mathrm{MeV}$ accelerator, is estimaled to be $\$ 43 \mathrm{M}^{8}$ 


\section{Assessment of Sources for ECH}

\subsection{Summary of Technologies}

The girotron, the Free Electron Laser (FEL), and the ('vciotron Auturesonance Maser (CARM) all require substantial additional development to meet the minimum CIT requirement of at loast $10 \mathrm{MW}$ average power at 280 GHz. Table 2 summarizes the present status of these possible suurces for CIT EC'H. Table 3 gives the major operating parameters such as electron beam vol:age. magnetic field. and efficiency.

\subsubsection{Gyrotron}

The gyrotrun is the best developed source lechnology al present. It appears very likely that $1 \mathrm{NWW}$, continuons wave (cw) uscillators at $280 \mathrm{GHz}$ can be developed. At $1.10 \mathrm{GHz} 0.1 \mathrm{MW}$ cw tube's are nuw available commercially with $0.4 \mathrm{HW}$ projected to be available soun. At $240 \mathrm{GHz}, 0.5 \mathrm{NW}$ in $2 \mathrm{~ms}$ pulses in a cw relevant tube design has also been experimentally demonstrated. Relatively moderate frequency $(<\times 2)$ and power scaling $(\times 3)$ are need $\mathrm{d}$ to meet the minimum Cl'T reyuirement with 11 or 12 one megawatt gyrotron tubes.

In addition to the relative advancerl state uf developinent, amother advantage of the gyrotron source terhnoligy is the selatively low eloctron beam vultage requirement. Existing neutral bearn power supplies at the TFTR site can be readily adapted to provide the necessary voltage and puwer. This would represent a significant cost savingș to (:IT installation.

However, there are several key issues that need to be comsidered in the development of a grrotron-based ECH system for CIT. These include: wall loading and higher order mode tube operation as the frequency is scaled to $280 \mathrm{GHz}$; the development of an efficient mode converter from the high order gyrotron nscillator mode to a low order mode useful for transmission and plasma heating; and the handling of many beams, up to 40, if a full 40 INW (:IT requirement is to be met with I MW tubes.

A potential future difficulty with the gyrotron is extension tu higher frequencios (>300 (illz), where difficulties increase significantly. lirwever, sorme performance with degraded puwer would be perhaps possible if magnets are designed for operation at a field higher than the nominal operating field. 


\subsubsection{IFEL (Induction Free Electron Laser)}

The induction linac driven FEL is the next best developed source technol. og:: is most likely form will be a rapidly pulsed amplifier. the oscillator driver at 280 ( $3 \mathrm{~Hz}$ being a low power (1-10 klit) backward wase gyrotion. In short pulse operation, $20 \mathrm{~ns}, 1 \mathrm{GW}$ at $35 \mathrm{GHz}$ and $50-100 \mathrm{MW}$ at $110 \mathrm{GHz}$ have been demonstrated. However, the pulse repetition rale to date has been very slow, $0.5 \mathrm{~Hz}$. and consequently the average power has been on the urder of 10 and 1 IV, respectively. Ti meet the minimum CIT requirement, the average power performance must be improved by a factor of about $10^{6}$. This improvement is experted to be achieved in large part by an increase in the pulse repetition rate to the order of $10^{-4} \mathrm{~Hz}$, using switching technology that has been demonstrated on injectors and acceleratur sections in the laboratury. An integrated test of this IFEL technology: will take place in the MTX program.

The main issue with the development af IFEIs for CIT is the achievement of high average power. Pulse repetition rates on the order of $\mathrm{I}^{4 / \mathrm{Hz}} \mathrm{Hr}$ higher are needed to demonstrate feasibility and to resulve unknuwns abom possible nonlinear plasma effects using very high peak power pulses for EC:II. Alsis. high cost and large size of 10 Mel electron beam acceleraturs make's the practicality of the IFEL very sensitive to the output prower amount.

\subsubsection{EFEL (Electrostatic Free Electron Laser)}

The elertrostatic accelerator driven FEL is in a similar state of development. In the concept of TRW, Inc., the EFEL is a rontinusus wave (rw) uscillator at unit power levels of 2-3 MW. Hesults to date in the $30-60 \mathrm{GHz}$ range at TRW and at 400 C $\mathrm{Hz}$ at the University of California at Santa Barbara have been much lower in peak and average power than those for the induction linar driven FEL.

The main advantages of FEL sources for CIT ECH are: readily scalable to high frequenry operation; fundamental or low order mode output directly usable for transmission/heating, and larger power tunit size reducing transmission line complexity. The FEL also has an advantage in frequenry tunability discussed below. 


\subsubsection{CARM (Cyclotron Autoresonance Maser)}

The (AKM is the least developed source techackegy proposed for (IT. Berause of its immalure state of deve]esment. its configuration for (IT has mot been determined. It could take the form of a rapidly pulsed amplifier ir oscillator or as a c.w uscillator in unit sizes of 2.3 . $\mathrm{HW}$ or larger. There are nu experimental resulis in the $\mathrm{U} . \mathrm{S}$. in this area at present though several groups (Generai Atornics (orporation, MIT, the Naval Research Laboratory, and the (injersity of (alifornia at Los Angeles) are initiating or planning experimental work. In the Sowiet Union there has been some experimental work at $125 \mathrm{GHz}$ and hwer frequencies. Velocity spresd effects are a key issuc to be investigated. The CARM can be viowed as providing the potential for an altractive compromise between the gyrotron and FEL technolugies. The accelerator requirement of approximately i MeV is mere than for a gyrotron $(\approx 100 \mathrm{kel})$ but less than for an FEL $(\approx 10 \mathrm{Mr} V$ ). Hence. the ( ARM would nperate in a low urder mode like an FEI but with a much smaller and less expensive accelerator. The (:ARM has the capability to operate at much higher frequencies than the gyrotron, herause its frequency depends on bean entergy as well as magnetic field.

\subsection{Frequency Tuning}

There are several potential needs for a frequency turing capability, deperrolding un the time scale of the tuning. Table $f$ sumunarizes the protential tuming capabilities of the possible CIT ECH sources.

On the shortest millisecond time scale, tuning can be used for profile control, sawtooth stabilization, of MHD instability feedtack control. The gyrotron uscillator has the least tuning capability on this time scalc due to the weak dependerice of the resonance frequency un voltage pulling. The FELs .pperated as amplifiers can have $6-10 \%$ instantaneous bandwidth which wonld correspond to all equivalent millisecond tuning range given a rapidly tunable oscillator driver. The CARM potentially could have the largest millisecond tuning capability because, in addition to an instantaneous bandwidth connparable to an $\mathrm{FEL}$, its $v_{1} / v_{\|}$electron bean wetucity ratio could be rapidly varied with a specialized electron gun. The Doppler shift term in the CARW frequency depends only an $u_{1}$.

On the linger second tinc scale. a $30 \%$ tuning capatsitity would be seeded 
for heating during toroidal field ramp-up and ramp-down. All the sources have the potential to meet this requirement. The gyrotron curld achieve this tuning cajability by mode hopping due th a sweep of its magnetic field in synchronism with the toroidal field. A $60 \%$ tuning range centered at $185 \mathrm{GHz}$ with $10 \mathrm{GHz}$ steps already has been demonstrated for a gyrotrun at MIT. Howeter, a specialized hybrid superconducting magnet with a copper core and a wide bandwidth mode converter would need to be developed. The FEL could have a large second tuning capability by varying the wiggler magnetic field strength as recently demonstrated by the Electron Laser Facility (ELF) at Lawrence Livermore National Laboratory (LLNL). The CARM could also have up to a $30 \%$ second tuning rapability by varying its magnetic field as well as the $v_{1} / v_{\| \mid}$electron beam velucity raticu.

A requirement fir a frequency change on a much longer time scale - in the order of day's or woeks - has alsw been stated. Slow frequency adjustments would be useful when (IT start-up operation at $7 \mathrm{~T}$ progresses to 10 T and pussibly ] ] T operation. If the second tuning capability as shown in Table $t$ is built into the sources from the start, then the requirement wonld be sat isfied. However, additional options exist for changing ECH surce frequency an time scales of a week. In the case of gyrotrons, the gyrotron twhe containing the electrin gun, resonator, and mode converter could be replaced, keeping the magnet, power supplies, and transmission line the same. The gyrotron tube, unce developed, represents a small lraction of the overall cust of a gyrotronbased ECH system. In the case of an FEL, the wiggler period or beam energy could be adjusted on day time scales to optimize performance at alternate frequencies.

\subsection{Breakdown (Arcing in Transmission)}

The power densities considered for CIT EC'H are high enuugh that breakdown in the transmission line should be investigated. Above a threshold powes density, breakdown occurs at millineter wave frequencies when a few injtial cectrons are accelerated by inverse bremsstrahlung absorption to energies surficient for ionizing gas molecules, producing additional electrons that continue the process until an electron density of greater than $10^{13} \mathrm{~cm}^{3}$ is produced. The resulting are cuss off further millimeter wave transmission and can be damaging to the ECH system. 
In a clear: gas, the initial electrons needed to start a breakdown generally are not present. However, in the presence of contamination such as dust particles or at the surface of a mirror in the transmissiun line, the intilial electrons can be readily produred by high peak fields.

For microwave electromagnetic beams with pulse lengths $>50$ ns, it has been shown that the breakdown threshuld in air is given approximately ly.

$$
J \approx 2.6\left(p^{2}+2 f^{2}\right)
$$

where $J$ is the powwer density in $W \mathrm{~cm}^{-2}, p$ is pressure in torr, and $\int$ is frequency in $\mathrm{GHz}$. For $280 \mathrm{GHz}$ at atmospheric pressure, this gives an approximate threshuld of $2 \mathrm{MW} \mathrm{cm}^{-2} .9$

For shorter pulses the breakdown threshold should scale inversely with the pulse length. However, data taken at $0.4 \mathrm{~mm}$ wavelength (second harmonic for (IT) with a poulsed $\mathrm{D}_{2} \mathrm{O}$ laser has shown an air breakdown threshold as low as $0.5 \mathrm{MW} \mathrm{rm}^{2}$ with 7 ns pulses. ${ }^{10}$ The air in these measurements was pre-innized by power densities as low as $1 \mathrm{NW} \mathrm{cm}^{-2}$ on a nearby surface.

Therefore, a conservative approach to avoiding breakdown in an air-filled transmission line for continuous power would be to design the E(Cll system so that power densities are less than $0.1 \mathrm{MW} \mathrm{cm}^{2}$. The peak puwer level of $\mathrm{cw}$ EC'H sources for CIT such as the $1 \mathrm{MW}$ gyrotrun and the $2-3 \mathrm{MW}$ TRW FEL is $\operatorname{low}$ enough that the beam power density ran be kept under $0.1 .1 \mathrm{WW}^{\prime} \mathrm{cm}^{2}$ in wayguide diameters as small as $10 \mathrm{~cm}$. Therefore, a conservative approach to the design of the transmission line with respect to breakdown is pussible.

With high peak power pulsed ECH sources such as a pulsed IFEL or CARM, a different approach to the problem is necessary. The program or the 1FEL at LLNL does consider that an evacuated waveguide is necessary. In fact, there will be no window between the ECIH source and the plasma for the MTX experiment, and there is no window planned for CIT. An analysis by E. B. Horsper of LLNL (see the appendix) conclindes that breakdown of the background gas in the quasi-optical transmission line will not be a problem. Morewver, the permitted gas pressures are much larger than required in the transmission line for cleanliness regarding the plasma and the IFEL suurce.

However, experiments will be needed of establish breakdown linits, which conld be related to effects not yet identified, such as micro-partick rontimination of the transmission line. 


\subsection{Decision Criteria}

The decision on which source technolugies are must appropriate for ('IT' wil) depend un a number of criteria. Possible criteria that could be used include:

I. Cunfidence level for meeting minimum objectives of performance and schedule:

2. Timetable to demonstrate important milestones;

3. Costs of both research and development and hardware;

1. Cost sensitivity to deviations from projected souree performance;

5. Flexibility to accommodate evolution of the CIT design (field. density. tunability) and physics uncertainties.

'The ranking of the variuus suurce technolugies by these criteria could alsor change with time as these technolugies mature. It would also be affected by the ('I'T' timetable. 


\section{Discussion of Possible Strategies}

\subsection{Spanning Initial and Final Parameters}

The EC'H power system on CIT is to begin $i$ Tesla operation in 1996. and continue for $1-4$ years at this field. [n the years $1997-9$ the level should be raised 1,10 and 11 Tesla.

There are three general approaches:

1. a tunable system which ran span the range from 180 to $280 \mathrm{CHz}$ ( $\bar{i}$ to 10 Tesla); this could be step-tunability, with steps on the scale of tens of $\mathrm{GHz}$;

2. an upgrade to the initial $180 \mathrm{GHz}$ system in which crucial frequencysensitive components are changed;

3. installation of a $280 \mathrm{GHz}$ system, which is uperated on $\bar{T}$ Tesla discharges lyy launching with enungh $k$. to resunate with elettrons unwing along ine field.

Tunability is the best. if it can be obtained. Hlinever. the difficulties of reaching reliable high power at $180 \mathrm{C}(\mathrm{Hz}$ may be encugh without the additional demands of optirinal operation at $280 \mathrm{GHz}$. Chosice number three adds the demands of $280 \mathrm{GHz}$ to the pussible physics uncertainties associated with using the Doppler shift w resonate with kower fields, and the engineering of a practical, adjustable mirror.

The approach taken depends on progress in the coming years of the development program. At the present moment, a plan involving an upgrade lowks faworable. bising the gyrotron approach as an example, a reasonable plan unight be the following: develop and install a $180 \mathrm{GHz}$ grrotron system for 1996. but design the superconducting magnets and power supplies to be uperable at 10 Tesla. When the turoidal magnetic field can be raised to 10 Tesla. upgrade ur replace the gyrotron cavity, gun. drift tube, and collector as necessary.

Less favorable in appearance is a plan to install a full 280 ( $\mathrm{GHz}$ system at the heginning and roperate it in a 7 Tesla environment for several years. I sing the Doppler shift intruluces new physics to the EC:H interaction. In particular, the luw field plasma has to lee pre-heated to a significant degres $w$ 
absorb power well. Also, it appears mure probable that reijable high power will exist at $180 \mathrm{CHz}$ than at $280 \mathrm{CHz}$ during the early years of ('IT.

\subsection{Second Harmonic Heating}

First harmonic heating (fundamental) has been discussed, rather than sec. und harmonic. This is because signiticant power is now available at 110 (illz with gyrotrons, which is comparable to the $180 \mathrm{GHz}$ required for $i$ Testa. $A$ secund harmonic system is 360 to $566 \mathrm{GHz}$. representing an enormus advance in the state of the art.

The second harmonic does have advantages in physirs. particularly the atsility to push the density much higher.

The strategy for ('IT' is to focus on n carly implementation of high power first harmonic heating. Depending on progress of the C'IT project itself and the $\mathrm{K} \& \mathrm{D}$ on EC'H surcess, a later decision to move the focus to second harmonic resuld appear advisable.

\subsection{Rapid Frequency Control and Feedback}

Fine tuning the frequency in short time scales to infuence plasma stability and confinement rould be advantageous. The technology to do this has not been develuped and the benefits have not been demonstrated. This element should be considered for addition tu the (IT program when technolugy and experiments are available.

As in section 4.2, the strategy for (IT is to forus on early implementation of high power heating. Depending on progress with sources and physirs ikx. [). rapid fine luning can be added, or some high puwer cquipment can be converted wa this purpose. 


\section{Conclusions}

There are now two main appsoaches to the technology of ECH sousces. The gyrotron leads in terms of energy at high frequency now delivered from a source, and an implementation of gyrotrons on CIT has the advantage of installed and paid-for DC; power from the TFTK neutral beam system. The IFEL holds the promise of tunability. The tunability has the putential for being rapid enough to follow the ramp of the magnetic field, and to follow: the location of certain magnetic surfaces in the plasma.

Important advances must occur with both the gyrotron and the IFEL to reach the performance desired for CIT. However, assuming adequate support is provided from now to the end of 1992, an informed evaluation of both technologies can br made in time to decide on the best path for (IT. Accordingly, the (IT schedule now shows a decision point regarding a commitment to the gyrotron and/or the IFEL at the end of 1992.

The best path may not involve a total system based entirely on one technolugy as upposed to the other. Assuming that both the gyrotron and the IFE: progress as hoped by 1992, a combination may be desired. For example, the gyrotron could provide the larger portion of the power while the IFEL. provides rapid tunability for interarting with the plasma on a fine scale. ('ombinations within a technology may be interesting. Consider 10 gyrotrons with different frequencies, or $1 F E L s$ with wigglers of different properties.

Funding is a concern, both for $R \& D$ and for a construction project. At present, the buik of the required $R \& D$ is supported, but, the construrtion funds have not been identified.

This document has focused on the gyrotron and the IFEL because they accupy the largest fraction of the support for microwave sources in the Office of Fusion Energy of the US Department of Energy. Other concepts deserve investigation, including the quasi-optical gyrotron, the cyclotron autnresonance maser, and the electrostatic free electron laser with energy recovery. 


\section{Acknowledgments}

This work was funded by the Inited States Department of Energy, (Office of Fusion Energy. The activity at PPPL was performed under Contract DEAC 02-76-CHO-3073. The work at MIT was supported by Contrart DE-AC0278ET-51013.

Material on physics requirements is based on presentations by R. Parker and D. Ignat, who used material from M. Porkulab, S. Kaye, G. Bateman, W. Reiersen, S. Jardin, and N. Pomphrey. Cimments received from T. R. James, K. Thomassen, E. B. Hooper, Jr., M. Porkolab, J. Casey, R. S. Post, and J. A. Schmidt have been incorporated. Advice from H. Jory and R. J. Temkin forms a background for the opinions expressed on the best aim for the development program on gyrotrions.

This repurt is adapted from ('IT Dusument AA-881018-PPL-05, which was requested of the CIT Project Office by the Department of Energy, Office of Fusion Energy. 
Appendix 1

\author{
Explicit form of Scaling Laws \\ by \\ D. W. Ignat and G. Bateman \\ Prinreton Plasma Physics Laboratory
}

Energy balance in ('TT is modelled in zero dimensions by setting the total input power equal to the powes flowing ont of the plasma. If $W$ is the total particle energy in the plasma, $\tau_{E}$ is the energy cunfinement time for cunduction, $P_{\text {Had }}$ is power radiated in parallel with conduction, $P_{O H}$ is the ohmir heating frum the plasma current, $P_{\alpha}$ is the power Irom alpha heating, and $P_{\text {Aur }}$ is the auxiliary heating power, then in steady state:

$$
P_{O H}+P_{\alpha}+P_{A u H}=H / \tau_{E}+P_{\text {Rad }} \text {. }
$$

The scaling laws under discussion segard the parametric variation of $\tau_{E}$ and $P_{\text {Had. }}$

We consider that discharges heated only by ohmic heating have one scaling law, and discharges with dominant auxiliary heating have another scaling law. For ohmic heating, the "You-Alcator" scaling"1 is used:

$$
T_{N-A}=0.0 \overline{7} \bar{n} a R^{2} q_{\text {eyl }}
$$

Fir discharges with strong auxiliary heating, one or the other of two scaling laws is discussed. The more favrathle :s "Kaye-Goldstom" scaling":

$$
\tau_{\kappa-C}=0.055\left(W, Z^{i / 2}\right)^{1 / 2} \kappa^{0.28} I^{1.24} P^{-0.58} a^{-0.49} R^{1.65} B^{-0199} \bar{n}^{0.26}
$$

and the less fawrable is "Guldstun-Aachen" scaling":

$$
\tau_{(i-A}=0.03 T(M / 1 . \overline{5})^{1 / 2} \kappa^{0.5} J^{1.0} P^{-0.5} a^{0.1 T} R^{175} .
$$

The quantities and units are as follows: 


$\begin{array}{ll}\tau & \text { Confinement time. seconds } \\ H & \text { Average mass of hrdrogenic species, amu } \\ \kappa & \text { Elungation ratio } \\ B & \text { Toroidal magnetic field. Tesla } \\ I & \text { Plasma current, Megarnperes } \\ n & \text { Line-averaged electron density, } 10^{20} / \mathrm{m}^{3} \\ P & \text { Auxiliary power (including alpha particle heating) } \\ & \text { in Megawatts } \\ a & \text { Minor radius (half-width at midplane), meters } \\ R & \text { Major radius, meters } \\ q_{\text {cyt }} & \text { cylindrical } q=5 a^{2} B\left(1+\kappa^{2}\right) / 2 /(I h)\end{array}$

To get one number for the confinement time, $\tau_{E}$, the laws from ohmic heating and auxiliary heating are combined according to an inverse square law. which has as its foundation the rule of reasonability:

$$
\left(1 / \tau_{E}\right)^{2}-\left(1 / \tau_{N} . A\right)^{2}-\left(1 / \tau_{d u x}\right)^{2},
$$

where $\tau_{A u x}$ is either of $\tau_{K}$ a: or $\tau_{G-A}$, depending on which scaling law for auxiliary heating is being considered.

The radiation term, Prad, includes bremsstrahlung, but neither line radiation nor squclurotron radiation, which are neglected. The formula ${ }^{12}$ adouted is:

$$
P_{\text {Rad }}=0.0168 Z_{\text {efJ }} \int_{\text {udumc }} n^{2} T^{1 / 2},
$$

where $Z_{e f f}$ is the effective ion rharge of the plasma, taken to be 1.5 in the examples in this document, and $T$ is the electron temperature in units of 10 kel:

One should note that the scaling laws termed Neo-Alcator, Kaye-Goldston, and Goldston-Aachen, were derived ignoring radiation. 'T'his means that radiative losses were included in the scaling laws. In this analysis the radiative losses are added explicitly to a form of energy confinement which already included radiation in a sense. This is dune to make sure that physically impossible results are not whatained at high densities and low temperatures where radiation is high. 
The calculations of Figures 1 through 3 include profiles for density and cemperature of the form

$$
n(x)=n(0)\left(1-x^{2}\right)^{a_{n}}
$$

and

$$
T(x)=T(0)\left(1-x^{2}\right)^{a_{T}}
$$

where $x$ is fractional distance from the center on the midplane. The powers $a_{n, T}$ are noted on the Figures.

The enhancement over Goldston scaling of 1.8 in Figures 2 and 3 refer $t$ an arbitrary multiplier on the formula above for $T_{G-A}$. 
Appendix 2

\author{
Breakdown in IFEL Quasi-Optical Transmission System \\ by \\ E. B. Hooper, Jr. \\ Lawrence Livermore National Laboratory
}

Summary The issue of breakdown of background gas in the quasi-optical transmission system is examined for a range of parameters including MTX and CIT. The parameters are far enough from breakdown conditions that no problems are anticipated. Surface breakdown is not analyzed here, but fields are much less than in the waveguide where it has been argued not to be a problem.

Analysis During the IFEL pulse, heating of stray electrons will cause expronentiation of the electron density although, as will be seen, the pulse length is short enough that the density will not build up very far. Following the julse, further jonization will occur as the electrons lose energy and the plasma recombines on the walls of the transmission line. At the low gas densities in the system, collisions are infrequent and the losses to the walls will be at the sound speed of the plasma.

The average electron density, $n_{e}$, in the transmission line will approximately vary as:

$$
d n_{e} / d t=\left[n_{v}\left(\sigma v_{e}\right) E \tau_{p} f-c_{s} / L\right] n_{e}
$$

Here, $n_{0}=p \times 3.5 \cdot 10^{16}$ is the gas density in $\mathrm{cm}^{-3}$, with $p$ the pressure in tor $\mathrm{r}$ : $\left\langle\sigma v_{e}\right\rangle$ is the ionization rate averaged over the electron distribution. $E$ is the enhancement coefficient due to ionization following the IFEL pulse. $T_{p}$ is the pulse duration, $f$ is the IFEL repetition rate, $c_{3}=10^{6} T_{e}^{1 / 2} / A$ is the speed of sound ( $w$ ith $T_{e}$ the electron temperature in $\mathrm{eV}$ and $A$ the atomic mass), and $I$ is the effective distance to the walls. 
We will get breakdown when the cuefticient of $n_{e}$ in the above formula is greater than 0 , so that the electron density can exponentiate. Thus, for there is be no breakdown, we require:

$$
\left.p<3 \cdot 10^{-11} T_{e}^{1 / 2} / !-A\left(\sigma v_{e}\right) E L \tau_{p} \rho\right) \quad .
$$

We use the maximum value of the ionization rate for our estimates:

\begin{tabular}{ll} 
Gas & $A\left(\sigma v_{r}\right)\left(\mathrm{cm}^{3} / \mathrm{sec}\right)$ \\
\hline hydrogen (gas or molecule) & $3.0 \cdot 10^{-8}$ \\
uxygen (gas or molecule) & $1.5 \cdot 10^{-6}$ \\
nitrugen (gas or molecule) & $1.3 \cdot 10^{-6}$ \\
argun & $8.0 \cdot 10^{-6}$ \\
\hline
\end{tabular}

The maxima all occur between 100 and $300 \mathrm{eV}$; for estimating purposes. take $T_{e}^{1 / 2}=16$ and $E=10$. We consider several applications:

\section{MTX}

- Hydrugen in the transport system; $L=30 \mathrm{~cm}, \tau_{p}=50 \mathrm{~ns}, f=5 \cdot 10^{i} \mathrm{~Hz}$,

$$
p<0.2 \text { torr }
$$

In the port. $L=3 \mathrm{~cm}$, and $p$ is about 10 times that in the transport. both here and in the examples below.

Oxygen and nitrogen in the transpurt system;

$$
p<4 \cdot 10{ }^{3} \text { torr. }
$$

Argon in the transport system;

$$
p<8 \cdot 10 \text { "torT. }
$$


These conditions are all easily met.

\section{CIT}

Dimensions and pulse lengths for (IT are similar. but $f$ could be as large as $2 \cdot 10^{4} \mathrm{~Hz}$. Thus, the limiting pressures are: hydrogen, $5 \cdot 10^{-2}$ torr; oxygen and nitrogen, $10^{-3}$; and argon, $2 \cdot 10^{-4}$ torr.

Discussion The lack of ionization largely arises from the fact that the minimum ionization time, $\left(n_{0}\left\{\sigma v_{e}\right\rangle_{\max }\right)^{-1}$, is long compared with the microwave pulse, 50 ns. For example, in hydrogen gas at $10^{-3}$ torr, the ionization time is 500 ns: and in argon at $10^{6}$ torr, the ionization time is $4(100$ ns. Thus, there is very little buildup of electesn density during a microwave pulse.

Finally, note that the permitted gas pressures are much larger than required in the transmission line for cleanliness and much larger than designed. Consequently, the crudeness of the model used in the analysis should not affect the conclusion that breakdown due to ionization of the backgiound gas will mot iscur. 


\section{References}

'S. Kaye and R. Goldston, Nucl. Fusion 25. 65 (1985).

${ }^{2}$ R. Goldston, Plasma Phys. Controlled Fusion 26, 87 (1981).

'S. C. Jardin, N. Pomphrey, and J. DeLucia, J. Comput. Phỵs. 66, 481 (1986).

'E. Mlazzucato, I. Fidone, and G. Granata, Phys. Fluids 30, 3745 (1987).

\$1. Purkolab, private communication.

6uCIT Physics Design Description," document number AE-88011\%-PPL-01. by K. Parker, D. Pust, G. Bateman, M. Bell, J. Casey, P. Colestuck, F. Dylla, H. Furth, M. Greenwald, W. Houlberg, M. Hughes, S. Jardin. S. Kave, R. Meyer, J. Manickam, C. K. Phillips, R. Pillsbury, M. Porkulab, R. Sayer, D. Sigmar, G. Smith, D. Stutler, D. Strickler, Y. Sun, K. Thomassen, A. Todd, M. Ulrickson, N. Uckan, H. Weiner, J. Wesley, S. Wolfe, K. Yunng. Section 3 contains a discussion of the density limit, and gives primary references.

7"(;IT Gyrotion ECRH Program," MIT Plasma Fusion Center report number PFC/IR-88-2, by J. A. Casey et. al., and "Generic R\&D Overview," CIT meruo AA-8811 3 - PPL-02, by D. W. Ignat.

8"Options for CIT - Initial Studies," presentation at a CIT Workshop on Heating, June 8-9, 1988, Livermore, CA, by R. Stone. See also CIT memo cited above.

${ }^{9}$ Wee Wioo and J. S. DeGroot, Phys. Fluids 27, 475-487, 1984.

10P. P. Woskoboinikow, J. Mulligan, H. R. Praddaude, and D. R. Gohn, Appl. Phys. lett. 32, 527-529, 1978.

${ }^{11}$ J. H. Parker et al, Nucl. Fusion 25, 1127 (1985).

${ }^{12}$ NKL Plasma Formulary, 1983. Original reierence on bremsstrahlung is given there as: S. Glasstone and H. H. Loveberg, Controlled Thermonuclear Reactions (Van Nustrand, New York, 1960), Chapter 2. 
Table 1: Selected Parameters of the CIT Design

Parameter

Majus Radius, $\mathrm{R}$

Halr-wideh. a

Half-height, $b$

('urrent, I

Start-up value

Torroidal Field, $\mathrm{B}$

Siart-up value

Fusion power at beta limit.

Flat top time

Number of pulses at full performance

Fusion energy released during lifctime

Trowon parameter, $\beta \% /(1 / \mathrm{aB})$

Murakanu parameter, $\mathrm{n}_{20} /\left(\mathrm{B} / \mathrm{R} q_{\varepsilon}\right)$

Elongation, kappa

Safety factor, 4 at $95 \%$ fllux

Triangularity

Enhancement wer Goldston scaling in order 10 achieve ignition at i0 $\mathrm{T}$

Enhancement wyer Kave-Goldston scaling in order to achieve ignition at $7 T$

\section{Value}

$2.1 \mathrm{~m}$

$0.65 \mathrm{~m}$

$1.3 \mathrm{~m}$

II MA

7.T MA

$10 \mathrm{~T}$

$7 \mathrm{~T}$

800 NWW

5 seconds

3000

6.5 Terajoule

3

2

2

3.2, at least

0.25, at least 
Table 2: Comparison of status of possible sources for CIT ECH

\begin{tabular}{|c|c|c|c|c|}
\hline & Gurotron & $\begin{array}{l}\text { IFEL } \\
\text { Induction } \\
\text { Free Electron } \\
\text { Laser }\end{array}$ & $\begin{array}{l}\text { EFEL } \\
\text { Electrostatic } \\
\text { Free Electron } \\
\text { Laser }\end{array}$ & $\begin{array}{l}\text { C.ARM } \\
\text { Cyclotron } \\
\text { Autoresonance } \\
\text { Maser }\end{array}$ \\
\hline $\begin{array}{l}\text { CW or } \\
\text { pulsed }\end{array}$ & $\mathrm{CW}$ & $\begin{array}{l}\text { Pulsed } \\
>10 \mathrm{GW}\end{array}$ & Either & Either \\
\hline $\begin{array}{l}\text { Probable } \\
\text { unit size } \\
\text { (av. power) }\end{array}$ & $1 \mathrm{MH}$ & 10 $\mathrm{MW}$ & 2-3 MW & $2-3 \mathrm{MW}$ \\
\hline $\begin{array}{l}\text { Ciurent } \\
\text { slatus } \\
\text { (av. power) }\end{array}$ & $\begin{array}{l}2 \cdot 10^{5} \mathrm{~W} 071 \mathrm{GH} z \\
1 \cdot 11^{5} \mathrm{~W} 0140 \mathrm{GHz} \\
\text { as oscillator }\end{array}$ & $\begin{array}{l}\text { I0 W@ 35GHz } \\
\text { I W@ I40GHz } \\
\text { as amplifier }\end{array}$ & $\begin{array}{l}<I W Q 30 \& \\
41 M G H z \\
\text { as oscilla- } \\
\text { tor and } \\
\text { amplifier }\end{array}$ & $\begin{array}{l}\text { Not demon- } \\
\text { strated in } \\
\text { U. S., some } \\
\text { results at } \\
125 G H z \text { in } \\
\text { USSR as } \\
\text { oscillator }\end{array}$ \\
\hline (jk. power) & $9 \cdot 10^{5} \mathrm{~W} @ 140 \mathrm{GHz}$ & $\begin{array}{l}10^{9} \mathrm{~W} @ 35 \mathrm{GHz} \\
10^{8} \mathrm{~W} @ 140 \mathrm{GHz}\end{array}$ & $4 \cdot 10^{4} W @ 400 \mathrm{GHz}$ & \\
\hline \multicolumn{5}{|l|}{$\begin{array}{l}\text { Improvement } \\
\text { needed }\end{array}$} \\
\hline av. power & $\times 10^{1}$ & $\times 10^{7}$ & $\times 10^{7}$ & - \\
\hline frequency & $\times 2$ & $\times 2$ & $x 1$ & -- \\
\hline Issues & $\begin{array}{l}\text { High order } \\
\text { mode compet- } \\
\text { ition, wall } \\
\text { loading, output } \\
\text { mode convert- } \\
\text { 'srs, windews, } \\
\text { and scaling to } \\
\text { high frequen- } \\
\text { ries }\end{array}$ & $\begin{array}{l}\text { Demonstration } \\
\text { of high repeti- } \\
\text { tion rates } 104 \\
\text { Hz, high peak } \\
\text { power plasma } \\
\text { nonlineari- } \\
\text { ties, large } \\
\text { physiral size, } \\
\text { and cost sen- } \\
\text { sitivity to umit } \\
\text { puwer size }\end{array}$ & $\begin{array}{l}\text { Very low } \\
\text { efficien- } \\
\text { cies, elec- } \\
\text { tron beam, } \\
\text { energy re- } \\
\text { covery not } \\
\text { demon- } \\
\text { strated, } \\
\text { costs }\end{array}$ & $\begin{array}{l}\text { No U. S ex- } \\
\text { periment- } \\
\text { al experi- } \\
\text { ence, sen- } \\
\text { sitive to } \\
\text { electron } \\
\text { beam qual- } \\
\text { ity }\end{array}$ \\
\hline
\end{tabular}


Table 3: Major Parameters of Pussible CIT ECH Sourers

\begin{tabular}{|c|c|c|c|c|}
\hline & Gyrotron & IFEL & EFEL & CARUI \\
\hline $\begin{array}{l}\text { Electron } \\
\text { beam } \\
\text { woltage }\end{array}$ & 11.09 .31 & $510 \mathrm{MV}$ & $5-10 \mathrm{MIV}$ & $\approx 1 \mathrm{MV}$ \\
\hline $\begin{array}{l}\text { Magnet ir } \\
\text { field }\end{array}$ & 11 testa & $\approx 1$ tesla & $\approx 1$ tesla & $\approx 5$ tesla \\
\hline $\begin{array}{l}\text { Elecirs- } \\
\text { magnetic } \\
\text { mode }\end{array}$ & $\begin{array}{l}\text { Iligh order } \\
>5 \text { foth }\end{array}$ & Fundartiental & $\begin{array}{l}\text { Funda. } \\
\text { mentad } \\
\text { or low } \\
\text { order } \\
<5 \text { th }\end{array}$ & $\begin{array}{l}\text { Fundamental } \\
\text { or low order } \\
<5 \text { th }\end{array}$ \\
\hline $\begin{array}{l}\text { Achieved } \\
\text { Wadt-Plug } \\
\text { Eficiency }\end{array}$ & $31) \%$ & $7 \%$ & $1-5 \%$ & \\
\hline $\begin{array}{l}\text { Theoretucal } \\
\text { Beam- } \\
\text { Efficiency }\end{array}$ & $50 \%$ & $50 \%$ & $5 \%$ & $30 \%$ \\
\hline $\begin{array}{l}\text { RF output } \\
\text { converters. } \\
\text { and trans- } \\
\text { pirt }\end{array}$ & $\begin{array}{l}\text { Dilficult. } \\
\text { (many beams, } \\
\text { very high } \\
\text { order mordes) }\end{array}$ & $\begin{array}{l}\text { Easie:. } \\
\text { (one fiında- } \\
\text { mental } \\
\text { mevde beam) }\end{array}$ & $\begin{array}{l}\text { Moderately } \\
\text { easy }\end{array}$ & $\begin{array}{l}\text { Moderatelv } \\
\text { casv }\end{array}$ \\
\hline
\end{tabular}

Table 4: Frequency Funability of Proposed Sources for CIT ECH

\begin{tabular}{|c|c|c|c|c|}
\hline $\begin{array}{l}\text { Tuning } \\
\text { Time Scale }\end{array}$ & Gyrotion & IFEL & EFEL & CARM \\
\hline Milliserends & $10.111 \%$ & $(j-10 \%$ & $6.110 \%$ & $111-21) \%$ \\
\hline Sirconds & $\begin{array}{l}\approx 50 \% \\
\text { (ster) tunability) }\end{array}$ & $\approx .510 \%$ & $\approx 511 \%$ & $211-30 \%$ \\
\hline
\end{tabular}




\section{Figures}

FIG. 1. Plasma operation contours of constant auxiliary power (in MW) required un maintain a certain density (ordinate) and temperature (abscissa). The zero power contour at low temperature represents ohmic heating. Ignition is at threshold on the zero power contour covering 6 to $20 \mathrm{kel}$ temperature. The scaling law assumed is that of Kaye-Goldston. Field and current are 10 Tesla and 11 MA. Soft operational limits on density and héta are shown by heavy solid lines. (G. Bateman)

FIG. 2. Plasma operation contours as in Fig. 1 according to the Goldston scaling law, enhanced by a factor of 1.8. This shows that $60 \mathrm{MW}$ of auxiliary power does not lead to ignition in the steady state. (G. Bateman)

FIG. 3. Contumes of constant energy multiplication (Q) for the case of Fig. 2. This shows, when examined in conjunction with Fig. 2, that an auxiliary power of $25 \mathrm{MW}$ leads to a $\mathrm{Q}$ of 10 . (G. Bateman)

FIG. 4. Reference waveform for 10 Tesla and 11 MA operation. The flat portion of the toroidal field and plasma current is reached at 7.5 seconds from the initiation of the current. Half current and $80 \%$ of magnetic field is reached 3 seconds earlier. (W. Reiersen)

FIG. 5. Reference waveform for 11 Testa and $11 \mathrm{MA}$ operation. The flat portion of the toroidal field and plasma curtent is reached at 7.5 seconds from the initiation of the current. Half current and $80 \%$ of magnetic fietd is reached 4 seconds earlier. Flat-top time is limited to 3 seconds at 11 Tesla. (W. Reiersen)

FlG. 6. Keference waveform for 7 Tesla and $7.7 \mathrm{MA}$ operation. The flat portion of the toroidal field and plasma cursent is reached at 7.5 seconds from the initiation of the current. Half current and $80 \%$ of magnetic field is reached 3 seconds earlier. This level of performance can be reached with fewer power supplies than in the case of Figs. 1-2. With the same power, the $t$ Tesla current and field ramp could be faster. ( $W$. Reiersen)

FIG. 7 . Plasma positiun versus time during a ramp of the discharge current frum ares to $11 \mathrm{MA}$. as shown by the najor radius (top) and minur radius (bottom). (S. Jardin and N. Pomphrey) 
FlG. 8. Equilibria during (a) ramp-up; (b) flat-top; (c) ramp-down. (S. Jardin and i. Putuphrey) 


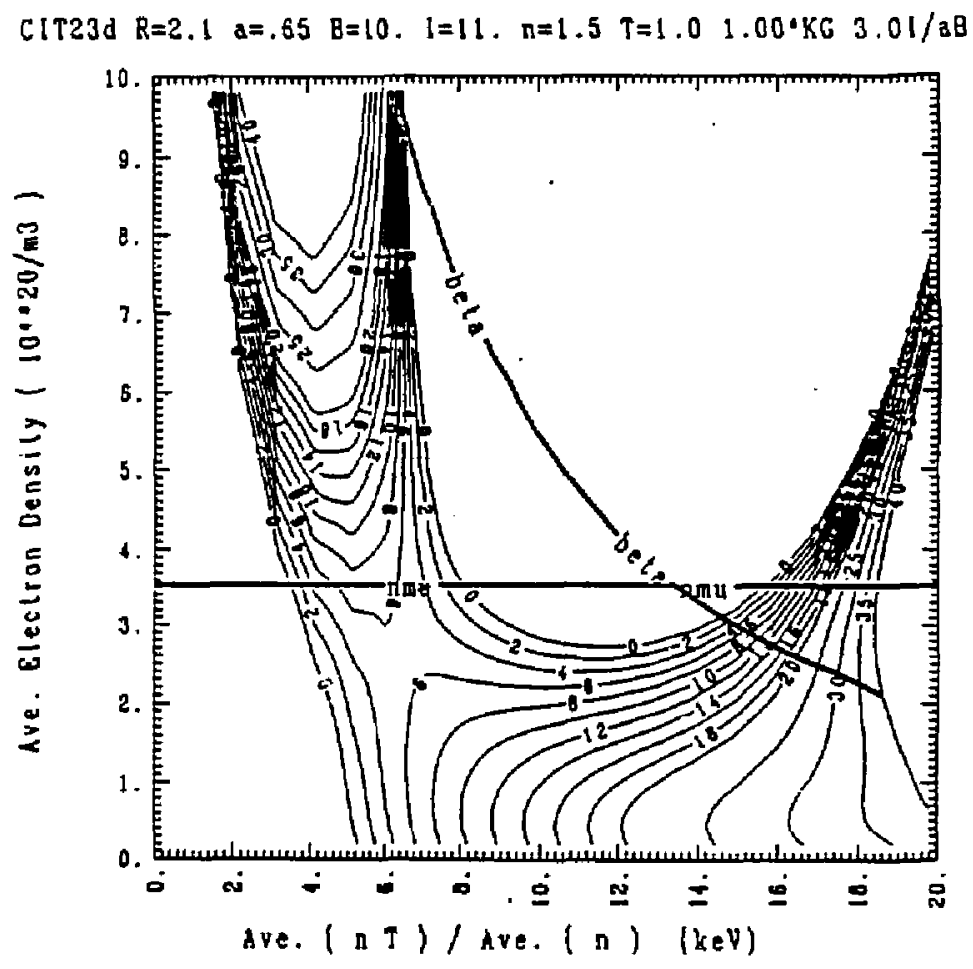

FIG. 1. Plasma operation contouss of constant auxiliary power (in MW) required to maintain a certain density (ordinate) and temperature (abscissa). The zero power contour at low temperature represents ohmic heating. Ignition is at threshold on the zero power contour covering 6 to $20 \mathrm{keV}$ temperature. The scaling law assumed is that of Kaye-Goldston. Field and current are 10 Tesla and 11 MA. Soft operational limits on density and! beta are shown by heayy solid lines. (G. Bateman) 
C1T20d $R=2.1 \mathrm{a}=.65 \quad B=10 . \quad I=11 . \quad n=0.5 \quad T=1.0 \quad 1.8 * \mathrm{C} \quad 3.01 / \mathrm{AB}$
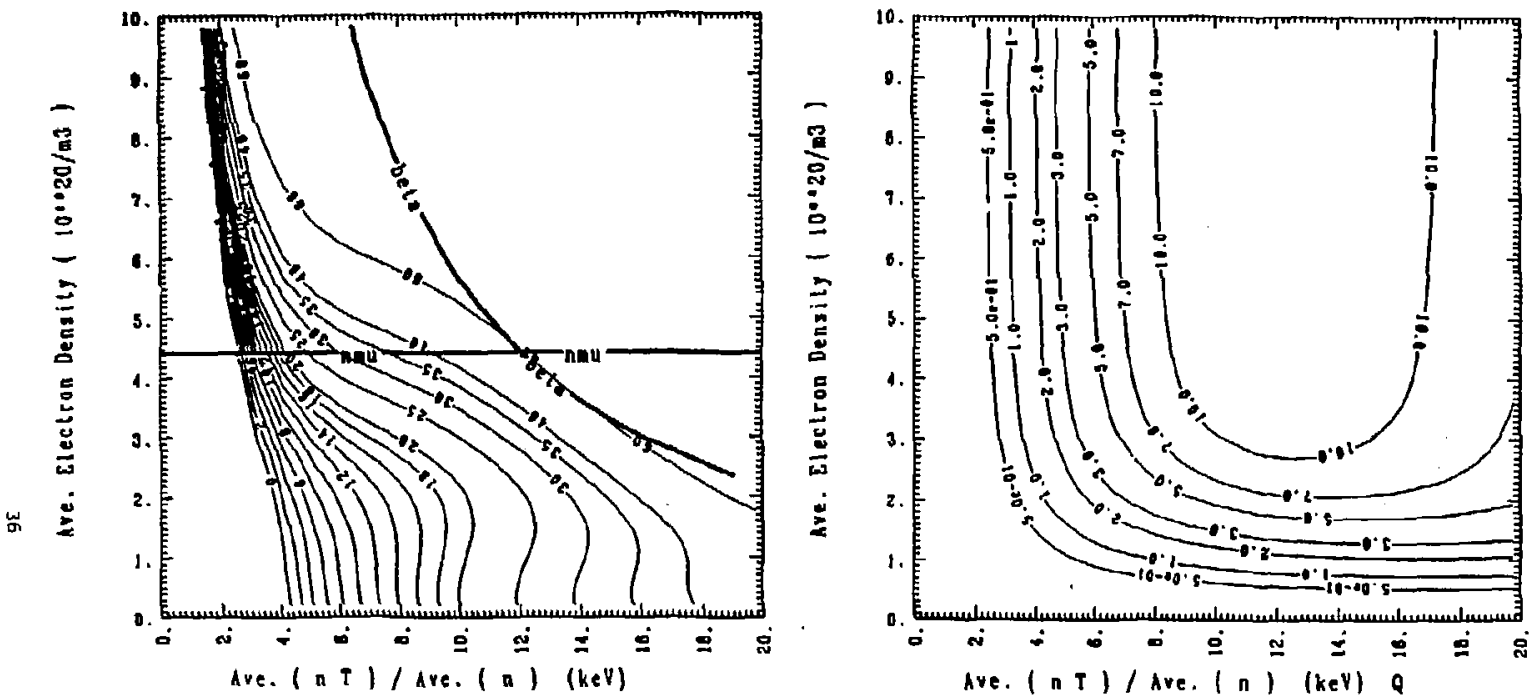

FIG. 2. Plasma operation contours as in Fig. 1 according to the Goldston scaling law, enhanced by a factor of 1.8. This shows that $60 \mathrm{MW}$ of auxiliary power does not lead to ignition in the steady state. (G. Bateman)

FIG. 3. Contours of constant energy multiplication (Q) for the case of Fig. 2. 'l'his shows, when examined in conjunction with l'ig. 2, that an anxiliary poiver of $25 \mathrm{MW}$ leads to a $\mathrm{Q}$ of 10 . (G. Hatcman) 


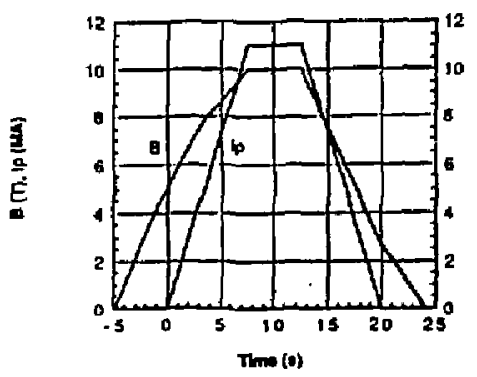

FIG. 4. Heference waseform for $10 \mathrm{Tes}$ a and 11 MA operatiun. The fat portion of the lorivilal field and plasmin curtent is reached at 7.5 seconds from the initiation of the current. Half rurrent and $80 \%$ of magnetic field is seached 3 seconds earlier. (W. Reiersen)

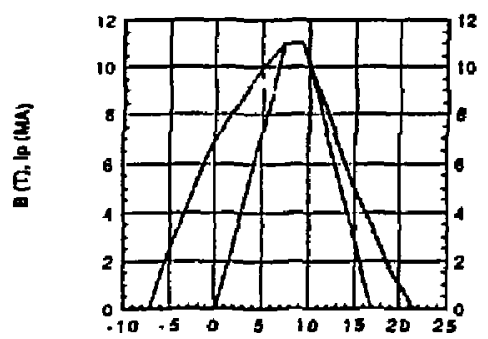

FIC. 5. Reference waveform for 11 Tesla and 11 MA operation. The flat port. tion of the Loroidal field and plasma current is reached at $\pi .5$ seconds from the intitation of the eurnent. Hall current and $20 \%$ of magneic field is react,ed 4 seconds earlike. Flat-lop time is limiteri to 3 secunds at II Tesla. (W. Reiersen)

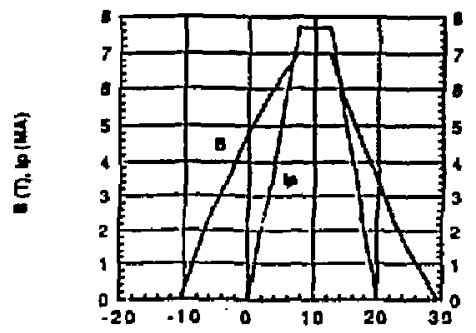

FIG: 6. Reference waveform for 7 Tesla and 7.7 MA uperation. The flat portion of the turoidal field and plasman current is reached at 7.5 seconds [rum the initiation of the cusrent. Half curent and $80 \%$ of magnetic field is reached 3 secunds earlier. This level of perfurmance can be teached with fewer power supplies than in the case of Figs. 1.2. With the same pooker. the $i$ Tesla curent and field ramp cruld he laster. (W. Heiersen) 

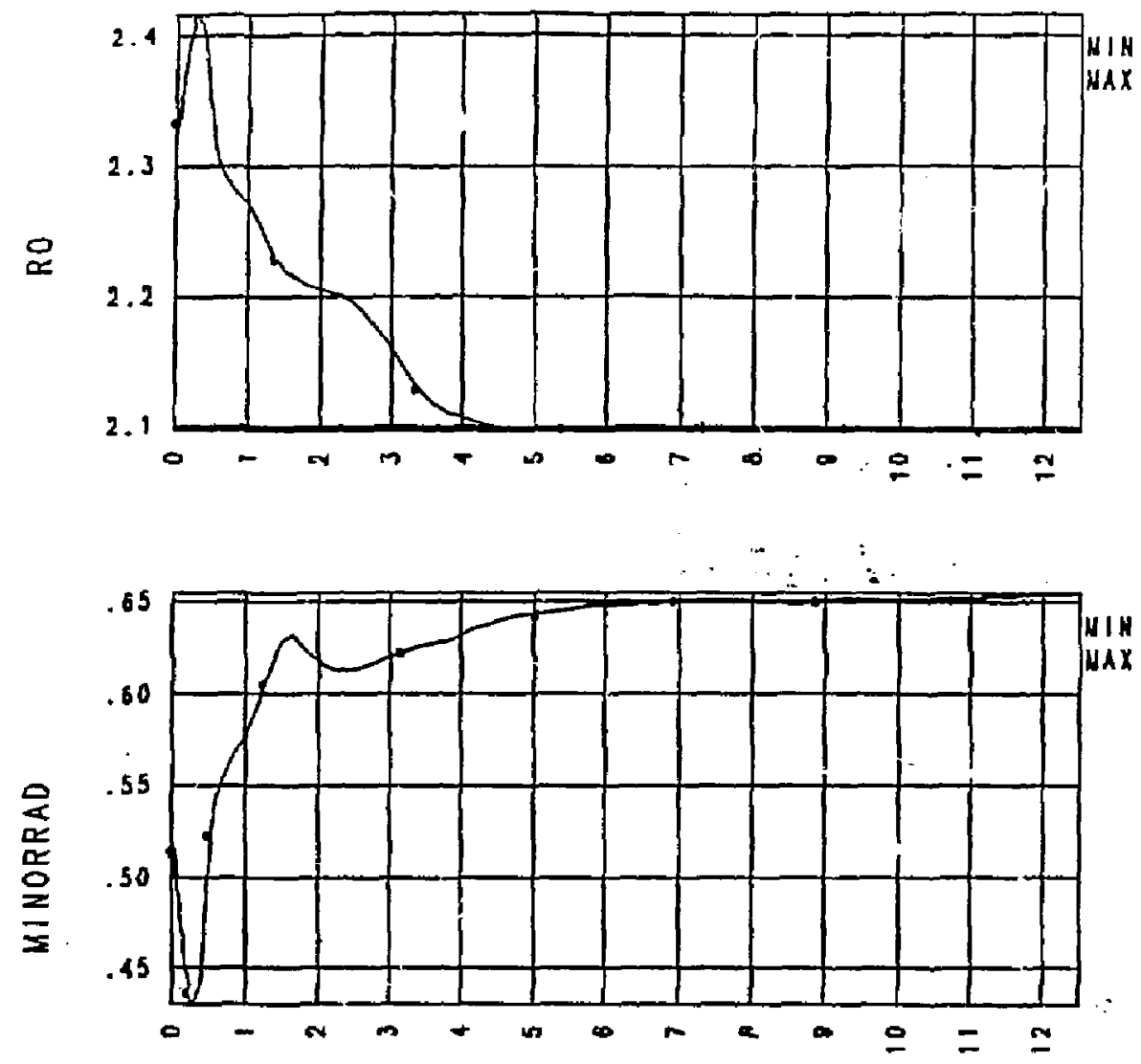

FIG. 7. Plasma position versus time during a ramp of the discharge current from zero to $11 \mathrm{MA}$, as shown by the major radius (top) and minor radius (bottom). (S. Jardin and N. Pomphrey) 


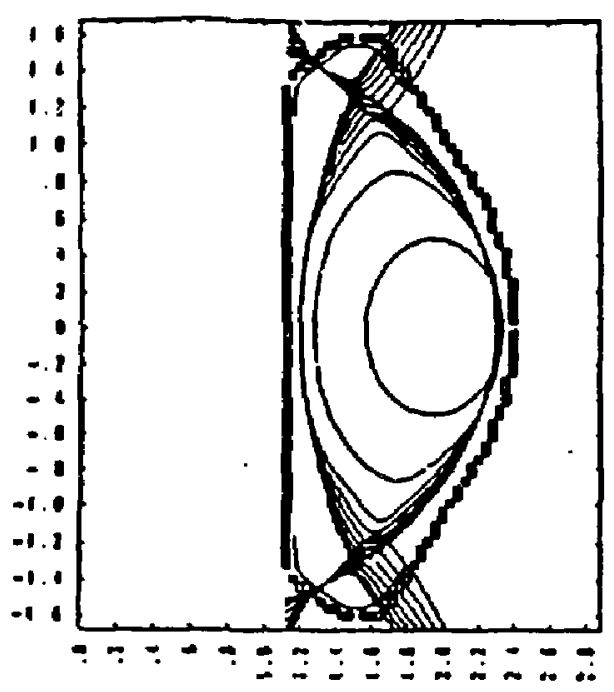

Qurrent Ines

$100 .-3.0$

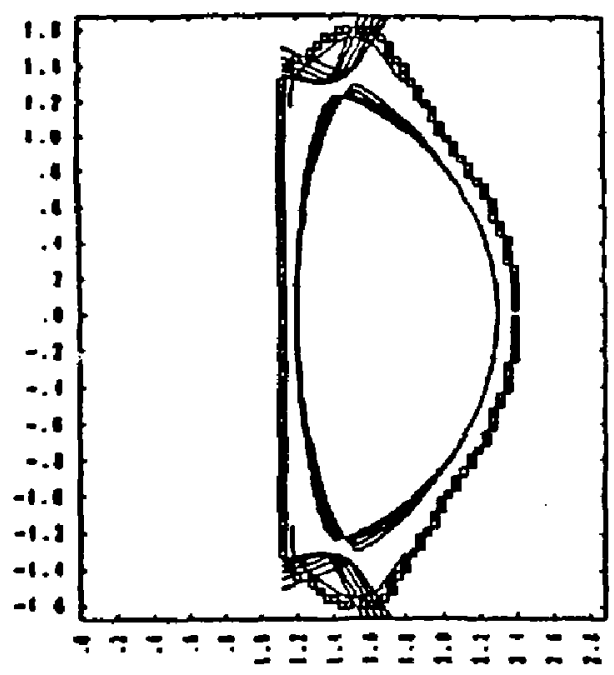

Current respdoun

$1-10.0 .+16.5$.

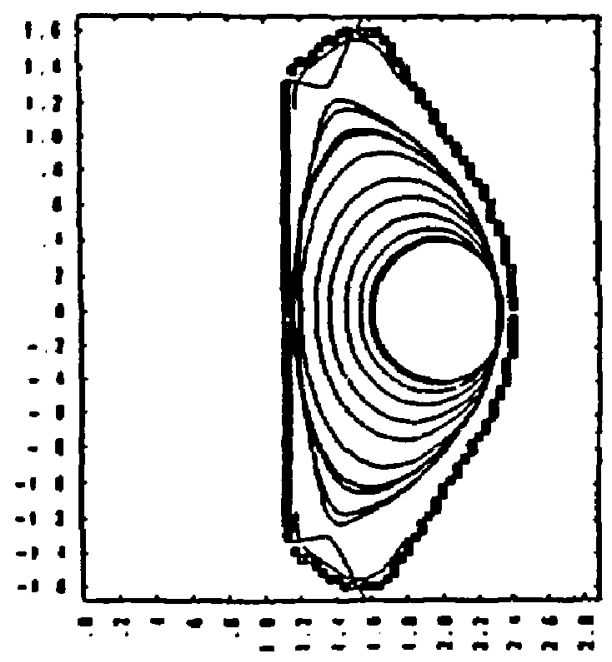

FlG. 8. Equilibria during (a) ramp-up; (b) flat-top; (c) ramp-down. (S. Jardin and N. Pomphrey) 
Dr. Frank J. Pooloni, Univ of Wol longong, AUStRaliA Prof. M.H. Brannan, Univ Syoney, austral iA Pl asea Research Lob., Australian Met. Univ., AUSTRALIA Prof. I.R. Jones, flinders Univ., AUSTRALIA Prof, F. Cap, Inst Theo Phys, AUSTRIA

Prof. M. Heindler, Institut fur Theoretische Physlk, AUSTRIA M. Coossens, Astronomiseh Instituyt, BELGIUM Ecole Royale Militaire, Lab de Phys PIasas, Belgium Comission-Eurogean, Dg-XII fusion Prog. Eelglun

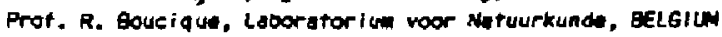
Dr. P.H. Sakanaka, Instituto Fisico, ERnzil Instituto De Posquisas Espociosi-IMPE, BRAzIL Documents offlee, Atomic Enargy of Canada Liaitad, CawaA Dr. M,P. Bachynski, MPe Technologies, Inc., Cavod Dr. H.M. Skarsgard, University of Soskatchowan, CANapa Dr. H. Barnard, University of British Columbig, CunaDh Prof. J. Telchmann, Unit. of Montreal, caukn Prof. 5.R. Sreenivasan, University of Calgary, Camon Prof. Tudor W. Johnston, INPS-Energie, Chukan Or. C.R. James, Univ, of Alberta, Ganad Or. Potar Lukac, Komenskeho Univ, CZECHOSLOVAKIA The Librarian, Culha Laboratory, EkcLANO The Librarian, Rutherford Applaton Laboratory, ENGLAND Wrs. S,A. Hutchinson, JET Library, EKGLAND

C. Mouttet, Lab. de Physique des Mll ieux Ionises, fance J. Rodert, CEN/CADARACHe - Bat 506, FRANCE Univ. of loannina, Library of Pnysles Oept. Gaeece Dr. Ton mal, Acaduly Blbliographic Ser., houn xans Preprint Library, Hungari an Academy of Sciances, Huksar Dr. 9. Desgupte, Saha Inst of Nucl. Phys., I DOIA Dr. P. Kaw. Institute for Pl asas Resegreh, INDIA Dr. Philid Posangu, Is rael inst. Teen, ISPAEL Librarian, Int'I Cor Theo Phys, ITALr Prof. G. Postagni, Univ Di Padova, ITALY Miss clelia De Palo, Assoc EURATOH-EkEA, ITALY Bibliotece, Instituto dl Fisice del PI asea, ITALY Or. H. Yanto, Toshibe Ras 5 Dov, JAPAN

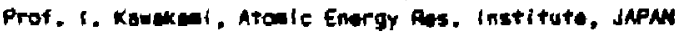
Prof, Kyojl Mishlkawa, Iniv of Hiroshime, JAPNY Diree, Dapt. Large Tokangh Ries. JAERI, JAPNY Prof. Satoshi Itoh, Kyushu Unlversity, JAPAY Rasearch Info Canter, Nagora University, JAPAN. Prot. 5. Tanaka, Kyoto Univarsity, JAPAM Library, Xyoto University, JAPN

Prof. Nobuyuki Inove, University of Tokyo, JAPNA S. Nor $i$, JAERI, JAPAN Librarian, Korat Advanced Energy Ras, Institute, KOREA Prof. D.1. Chol, Adv. Inst Sel \& Tueh, KOPEA Prof. B.5. Liley, University of Walkato, NEW IEALAND Instituta of Plase Physles, PEOPLE's repLalic of CHIN

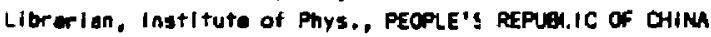
Librery, Tsing Hus University. PEOPLE'S REPUaLIC of CHIM
2. LI, Southwest Inst. Physics, PEOPLE's RePUBLIC of CHIM Prof. J.A.C. Cabral, Inst Superior Teenico, PORTUGAL Or. Octavlan Petrus. Al I Cuzh University, RowwiA Dr. Johen de Villiers, Fusion Studies, AEC, SO AFRICA Prof. M.A. Hel Iberg, University of Matal, SO AfRICh C.I.E.M.A.T., Fusion Div. Library, SPAin Dr. Lonnart Stenflo, University of UMEA, SHEDEM Librory. Royal Inst Tech, SWEOEN Prot. Hans wilhelason, Chalmers Univ Tech, SWEDEN Contre Phys das Plasad, Ecole Polytech Fed, SwITZERLANo BIbl iotherk, fou-inat Voor Plasma-Fysica, THE MEFHERLAMOS Dr. D.D. Ryutov, Siberian Acad Sci, USSR Dr. G.A. Elisevy, Kurchatov Institute, USSR Dr. V.A. GIukhikh, Inst Electrophysical ADparatus, USSR Or. V.T. Tolok, Inst, Phys. Tech. USSR Dr. L,M. Kourizhnykh, Institute Gen. Physles, USSA Nuclear Res. Establishnent, Julich Ltd., W. GERMNY Bibliothak, inst. Fur Plasmaforseheng, W. GEFuNY Dr, K, Sehindler, Ruhr Universitat Boshum, w. GERany ASOEX Raoding Ror, IPP/Max-Planck-Inst I tut fur

Plasmaphysik, M. GEFuny Librarian. Maxfianck Institut, H. GEPaAkT Prof, R.K. Janew, Inst Phys, Yucoslavia 